\title{
Oocyte development in cattle: physiological and genetic aspects
}

\author{
Jack H. Britt
}

Institute of Agriculture, University of Tennessee, Knoxville TN 37996 USA

ABSTRACT - Oocytes in cattle are formed during embryogenesis and develop within individual follicles in the cortex of the ovary. Dormant primordial follicles become active and undergo progressive development at regular intervals commencing during the late fetal stage and continuing throughout adulthood. Once activated, follicles and oocytes in a cohort either grow to maturation and ovulation or undergo atresia, ultimately depleting the ovaries of germ cells. It takes an estimated 100 days for a follicle and its oocyte to reach the mature ovulatory stage. Within an individual, number of follicles in one ovary is similar to number in the other ovary; however, there are large differences among individuals in total number of follicles present in both ovaries. In follicles that are recruited into the preovulatory pool, the fluid filled antrum enlarges and growth can be monitored by ultrasonography. Preovulatory follicles grow in waves rather than in a continuous stream, and number of follicles detected in a wave is related positively to number of microscopic follicles populating the ovarian cortex. Number of follicles in a wave is highly repeatable and the estimated heritability of number of follicles in heifers is approximately 0.35 . Monitoring preovulatory follicle numbers by ultrasonography can be used to identify females that produce more embryos following superovulation or more natural twin births. Number of follicles in a wave can be influenced by energy balance and exogenous hormones, and quality of oocytes within those follicles can be influenced environmental factors, hormones and vitamins. The potential exists to increase genetic progress through repeatedly harvesting oocytes from preovulatory follicles of genetically superior females.

Key Words: Bovine, Follicle, Ovary, Oocyte, Embryo, Fecundity,

\section{Introduction}

During development of the embryo, cells from the inner cell mass undergo differentiation to become specialized stem cells that form various tissues of the fetus. Some stem cells become primordial germ cells, which are precursors of oogonia in the female and spermatogonia in the male. Primordial germ cells migrate from the embryonic yolk sac to the genital ridge and populate the developing gonads -- the bilateral ovaries of the female and the bilateral testes of the male.

Primordial germ cells in the bovine female fetus differentiate into oogonia during the first trimester of gestation. Oogonia divide mitotically well into the second trimester of gestation, generating a peak of approximately 2.7 million germ cells around day 110 of gestation (Erickson 1966a). During the second trimester, oogonia form egg nests in the ovarian cortex and enter the first prophase of meiosis where they become arrested in the diplotene stage. Somatic germinal epithelial cells from the surface of the ovary invade the egg nests and form a single flattened layer of epithelial cells around each oocyte. The primordial follicle comprises the arrested oocyte surrounded by the single layer of epithelial cells.
Once the primordial follicle is formed, the follicular epithelial cells that are in direct contact with the oocyte interact through localized cellular signals to regulate oocyte maturation. Follicle growth is regulated by signals between the oocyte and surrounding epithelial cells and between the epithelial cells and other somatic cells in the ovarian cortex and by signals emanating from systemic circulation.

Some primordial follicles that populate the fetal ovary begin to grow during the second trimester of gestation, but most remain in an arrested state. Growth is characterized first by enlargement of the flattened epithelial cells to become cuboidal-shaped granulosa cells. Next, the arrested oocyte increases in size and surrounding granulosa cells divide to form multiple layers. Ultimately a fluid-filled central antrum forms and partially surrounds a cluster of cumulus granulosa cells surrounding the oocyte.

Once follicles start growing there are two possible fates, atresia and elimination of the follicular cells and oocyte through apoptosis and other mechanisms or full maturation and ovulation of the oocyte. Ovulation only occurs in postpuberal females that are undergoing estrous cycles, so most oocytes are lost through atresia. In fact, about two-thirds of the original population of germ cells is the fetus are lost by 
the time of birth. Nevertheless, hundreds of thousands of oocytes are present in a neonatal calf's ovaries and thousands can remain in the ovaries of mature cows (Erickson 1966b). Thus there is an opportunity to capitalize on this underused source of germ plasm to accelerate rate of progress in genetic selection and to enhance fecundity in livestock. This paper will focus on some of the practical aspects of managing follicle growth to produce more oocytes, embryos and live births from cattle.

\section{Folliculogenesis}

The microscopic appearance of follicles in a histological section of ovarian tissue from a mature cow is illustrated in Figure 1. The primordial follicle $\left(0^{\circ}\right)$ includes an oocyte with a visible nucleus surrounded by a single flattened layer of granulosa cells. The primary follicle $\left(1^{\circ}\right)$ includes a larger oocyte with a visible nucleus surrounded by cuboidal granulosa cells. The larger secondary follicle $\left(2^{\circ}\right)$ includes an enlarged oocyte (nucleus is not visible in this section) surrounded by 3 to 4 layers of cuboidal granulosa cells. The cytoplasmic membrane of the oocyte in the secondary follicle appears thicker because the zona pellucida layer has been secreted by the oocyte.

The estimated time course of folliculogenesis in the bovine is 80 to 100 days (Britt, 1991; Figure 2). Primordial follicles may undergo progressive development soon after they are formed or they may remain dormant for years before beginning further development. It is believed that primordial follicles are kept dormant by factors that reach the follicle through the vascularized ovarian cortex, because primordial follicles undergo spontaneous activation if they are isolated and cultured in vitro (Cushman et al., 2002; Yang and Fortune, 2008).

Once progressive follicle growth begins, there are a number of local and systemic regulatory factors that are required to sustain growth of the follicle to the fully mature Graafian stage preceding ovulation (Figure 2). These factors include metabolic regulators such as insulin and insulin-like growth factor I (IGF-I), steroids such as estradiol and testosterone, gonadotropins, and a broad array of growth factors that regulate cellular differentiation and multiplication. The number of growth factors and hormones that regulate folliculogenesis are beyond the scope of this review, but a few will be mentioned in the context of manipulation of follicular development.

\section{Relationships among Populations of Follicles}

In the last decade, much has been learned about relationships among various classes of follicles that populate the ovary. For example, we conducted studies to determine how the population of primordial follicles in ovaries of cattle was related to populations of growing follicles and whether the population in any follicle class was related to number of ovulations after superovulation (Cushman et al., 1999; Cushman et al., 2001a). Non-lactating Holstein and Jersey heifers and cows had one ovary removed for histological evaluation and were then given FSH to stimulate superovulation of the remaining ovary. The number of ovulations (corpora lutea, CL) was counted approximately 6 days after ovulation. Based on number of $\mathrm{CL}$, cows were classified as Low ( $<5 \mathrm{CL}, \mathrm{n}=9$ ), Medium (5-14 CL, $\mathrm{n}$ $=9)$ or High $(>14 \mathrm{CL}, \mathrm{n}=8)$ responders. We also classified cows on an observed bimodal distribution of microscopic follicles (Suboptimal, $<100$ microscopic follicles, $\mathrm{n}=5$; Optimal, $>250$ microscopic follicles, $\mathrm{n}=$ 21). Cows that were Low responders had fewer primordial, primary, secondary and tertiary follicles than cows that were Medium or High responders (Figure 3). Moreover, cows that were Medium or High responder had more visible surface follicles than Low responders. Cows with Suboptimal populations of microscopic follicles had fewer CL than cows with Optimal populations $(4.3 \pm 3.1$ vs. $12.5 \pm 1.7)$.

We also treated cows with hormones for 10 weeks to determine whether we could stimulate activation of primordial follicles and sustain their growth to ovulation (Cushman et al., 1999; Cushman et al., 2001b). The hormones administered were estradiol$17 \beta$ (E2), because we believed that it would stimulate more follicles to move into the primary follicle pool, and bovine somatotropin (bST), because we thought it would increase endogenous levels of IGF-I and thereby stimulate more follicles to survive to maturity. Control cows received no treatment and those given hormones received $\mathrm{E} 2$, bST or $\mathrm{E} 2+\mathrm{bST}$ continuously for 10 to 11 weeks. After an average of 73 days of treatment (Day 8 
of an estrous cycle), one ovary was removed surgically to assess populations of follicles of various classes. On the next day, cows were then treated with FSH and prostaglandin F2 $\alpha$ to induce superovulation and estrus and the number of ovulations was determined 7 days after estrus. We observed that treatment with E2 stimulated activation of primordial follicles and in combination with bST reduced atresia of primary follicles (Table 1). Thus, there were more growing follicles in cows given E2+bST and this increased the ovulatory response to FSH. These results mean that it may be possible to use various pharmacological treatments to increase number of growing follicles in cattle, and oocytes could be harvested from these growing follicles by serial oocyte ultrasound-guided retrieval or by superovulation.

\section{Evidence that Number of Preovulatory Follicles is Repeatable and Heritable}

Once follicles reach approximately 1 to $3 \mathrm{~mm}$ in diameter, their development can be monitored by ultrasonography. Thus, one can count how many follicles are recruited as a cohort in a follicular wave and determine whether the number is repeatable over time. Burns et al. (2005) counted the number of antral follicles $\geq 3 \mathrm{~mm}$ in diameter during follicular waves in Holstein heifers and cows. They found that overall repeatability of number of follicles among 138 follicular waves in 44 cows and heifers was 0.95 . Furthermore, they observed a repeatability of 0.85 among waves that occurred 15 months apart in the same animals. Thus one can identify individual animals or populations of animals that have more antral follicles and would be expected to have more in the future.

Monozygotic twins are genetically identical and one would expect a set of twins to have similar number of follicles and oocytes, especially if there is a genetic basis for this trait. Number of oocytes recovered by ovum pick up (OPU) was compared among nine pairs of monozygotic German Simmental twin cows (Figure 4, Machado et al., 2006). Each cow was subjected to 11 OPU sessions and data were compared within each pair and among the nine pairs. There was much less variation within each pair of monozygotic twins than among the 9 pairs, indicating that there may be a genetic basis for number of follicles reaching maturity.

Differences among breeds in the number of follicles detectable by ultrasonography were reported by Alvarez et al. (2000). Brahman and Senepol cows had a greater number of small antral follicles than Angus cows on all days of the estrous cycle. These breed differences provide further support for the concept that there is a genetic component to the number of follicles developing to the antral stage. If a larger number of follicles is truly associated with increased reproductive capacity, this may suggest that there are breed specific optimal numbers, because Brahman and Senepol cows are not as fertile as Angus cows.

Populations of microscopic and visible follicles in cattle selected for twin ovulations as heifers (twinner population) have been assessed. Compared with ovaries from unselected cattle, ovaries from the twinner population have more microscopic secondary follicles (Cushman et al., 2000) and more small ( $\geq 5 \mathrm{~mm}$ ), medium $(5.1$ to $9.9 \mathrm{~mm})$ and large $(\geq 1.0 \mathrm{~mm})$ surface follicles (Echternkamp et al., 2004). In twinner cattle, the heritability of ovulation rate is 0.35 and there is a high genetic correlation (0.75) between ovulation rate and twinning rate (Gregory et al., 1997); therefore, one can theoretically use routine ultrasound evaluation to select females that produce more follicles, more oocytes and more embryos in assisted reproduction programs (Figure 5; De Roover et al., 2005).

\section{Examples of Factors that Affect Follicle and Oocyte Quality}

Once primordial follicles are activated and begin development, the follicles may be subjected to conditions that ultimately affect quality of follicles and oocytes at the time of ovulation. During the 3-month period from activation to ovulation, a follicle might be growing in a cow subjected to heat stress, nutritional stress, disease or other factors that could impair the follicle-oocyte complex. Or the follicles and oocytes might be subjected to nutritional, dietary or hormonal environments that are beneficial. There are a number of practical examples of how bovine oocytes are affected by conditions that exist during their development. 
Temperature stress. Dairy cows subjected to high temperature stress during the summer in Israel continue to produce lower quality oocytes after high temperatures have moderated in the fall (Zoth et al., 2002). When heat-stressed cows are treated with bovine somatotropin (bST) or follicle stimulating hormone (FSH) about 3 weeks before ovulation, the quality of oocytes improves, either because of the beneficial effects of these hormones on the developing follicle and oocyte complex or because younger, healthier follicles are recruited into the ovulatory pool by the hormone treatments.

Energy balance. Dairy cows that lose more body condition during the first 5 weeks postpartum exhibit a more negative energy balance than those that lose less body condition. Cows that exhibit more negative energy balances apparently expose developing follicles to more adverse hormonal conditions such as lower levels of insulin-like growth factor I (IGF-I), insulin or gonadotropins (Figure 3), and these cows have lower fertility at 12 weeks postpartum (Britt, 1991). Bovine preantral follicles isolated from slaughterhouse ovaries estimated to be in the early postpartum period grew slower during a 5-day culture period than those isolated at other times in the production cycle (Figueiredo et al., 1994). Clearly, follicles and oocytes undergoing early development during negative energy balance are compromised.

Several studies conducted by Gong and colleagues (reviewed by Gong, 2002) provided evidence that insulin and IGF-I act in synergy to promote growth of more antral follicles. In one study, heifers fed diets $(200 \%$ of maintenance) to promote higher energy balance had higher blood concentrations of insulin, more preovulatory antral follicles and twice as many ovulations in response to exogenous gonadotropins as heifers fed control $100 \%$ of maintenance.

Vitamins. We discovered that treatment of gilts or sows with vitamin-A increased litter size (Coffey and Britt, 1993). Subsequently we showed that this was due to an effect of vitamin-A on oocyte quality (Whaley, 2000). We also showed that treatment of cattle with vitamin-A before superovulation resulted in production of more transferrable embryos (Shaw et al., 1995) . Vitamin-A apparently works directly on the oocyte, because incubation of heat-stressed oocytes with retinol prevented the adverse effect of heat stress on development of oocytes to the blastocyst stage (Lawrence et al., 2004).

The natural precursor for vitamin-A is $\beta$-carotene, and when it was combined with vitamin-E and injected into cows and heifers undergoing superovulation, it increased the quality of embryos in cows, but not heifers (Sales et al., 2008). Differences in responses between heifers and cows could be due to changes in cellular integrity associated with aging, lactational status, nutritional status or other factors.

\section{Summary}

Oocytes develop within ovarian follicles and number follicles growing in follicular waves of postpuberal cattle are repeatable and moderately heritable. Number of preovulatory follicles can be counted accurately by ultrasonography and can be used for genetic selection or for identifying animals that will produce more oocytes through ovum pick up or superovulation. Quality of follicles and oocytes is affected by factors such as temperature stress and energy balance. Certain pharmacological regimens can be used to increase number of oocytes harvested through assisted reproduction technologies.

\section{References}

ALVAREZ, P.; SPICER, L. J.; CHASE, C.C. et al. Ovarian and endocrine characteristics during an estrous cycle in Angus, Brahman, and Senepol cows in a subtropical environment Journal of Animal Science, v.78, n.5, p.1291-1302, 2000.

BRITT, J. H. Impacts of early postpartum metabolism on follicular development and fertility. The Bovine Practitioner Proceeding, v.24, p.39-43, 1991.

BURNS, D. S.; JIMENEZ-KRASSEL, F.; IRELAND, J. L. H. et al. Numbers of antral follicles during follicular waves in cattle: Evidence for high variation among animals, very high repeatability in individuals, and an inverse association with serum follicle-stimulating hormone concentrations. Biology of Reproduction, v.73, n.1, p.54-62, 2005.

COFFEY, M. T.; BRITT, J. H. Enhancement of sow reproductive performance by $B$-carotene or vitamin A. Journal of Animal Science, v.71, p.1198-1207, 1993.

CUSHMAN, R.A.; DeSOUZA, J. C.; HEDGPETH, V.S. et al. Effect of long-term treatment with recombinant bovine somatotropin and estradiol on hormone concentrations and ovulatory response in superovulated cattle. Theriogenology, v.55: n.7, p.1533-1547, 2001a.

CUSHMAN, R.A.; DeSOUZA, J. C.; HEDGPETH, V.S. et al. Alteration of activation, growth and atresia of bovine preantral follicles by long-term treatment of cows with estradiol and recombinant bovine somatotropin. Biology of Reproduction, v.65, n.2, p.581-586, $2001 \mathrm{~b}$. 
CUSHMAN, R.A.; DeSOUZA, J. C.; HEDGPETH, V.S. et al. Superovulatory response of one ovary is related to the micro- and macroscopic populations of follicles on the contralateral ovary of the cow. Biology of Reproduction, v.60, n.2, p.349-354, 1999.

CUSHMAN, R. A.; HEDGPETH, V. S.; ECHTERNKAMP, S. E. et al. Evaluation of numbers of microscopic and macroscopic follicles in cattle selected for twinning. Journal of Animal Science, v.78, n.6, p.1564-1567, 2000.

CUSHMAN, R. A.; WAHL, C. M.; FORTUNE, J. E. Bovine ovarian cortical pieces grafted to chick embryonic membranes: A model for studies on the activation of primordial follicles. Human Reproduction, v.17, n.1, p.48-54, 2002.

De ROOVER, R.; BOLS, P. E. J.; GENICOT, G. et al. Characterization of low, medium and high responders following FSH stimulation prior to ultrasound-guided transvaginal oocyte retrieval in cows. Theriogenology, v.63, n.7, p.1902-1919, 2005.

ECHTERNKAMP, S. E.; ROBERTS, A. J.; LUNSTRA, D. D. et al. Ovarian follicular development in cattle selected for twin ovulations and births. Journal of Animal Science, v.82, n.2, p.459-471, 2004.

ERICKSON, B.H. Development and radio-response of the prenatal bovine ovary. Journal of Reproduction and Fertility, v.10, n.1, p.97-105, 1966a.

ERICKSON, B.H. Development and senescence of the postnatal bovine ovary. Journal of Animal Science, v.25, n.3, p.800905, 1966b.

FIGUEIREDO, J. R.; HULSHOF, S. C. J.; Van den HURK, R. et al. The physiological status of the ovarian donor affects in vitro development of isolated bovine preantral follicles Theriogenology, v.42, n.8, p.1303-1310, 1994.

GREGORY, K.E.; BENNETT, G. L.; VAN VLECK, L. D. et al. Genetic and environmental parameters for ovulation rate, twinning rate, and weight traits in a cattle population selected for twinning. Journal of Animal Science, v.75, n.5, p.1213-1222, 1997.

LAWRENCE, J. L.; PAYTON, R. R.; GODKIN, J. D. et al. Retinol improves development of bovine oocytes compromised by heat stress during maturation. Journal of Dairy Science, v.87, n.8, p.2449-2454, 2004.

MACHADO, S. A.; REICHENBACH, H.-D.; WEPPERT, W. et al. The variability of ovum pick-up response and in vitro embryo production from monozygotic twin cows. Theriogenology, v.65, n.3, p.573-583, 2006.

ROTH, Z.; ARAV, A.; BRAW-TAL, R. et al. Effect of treatment with follicle-stimulating hormone or bovine somatotropin on the quality of oocytes aspirated in the autumn from previously heat-stressed cows. Journal of Dairy Science, v.85, n.6, p.1398-1405, 2002.

SALES, J. N. S.; DIAS, L. M. K.; VIVEIROS, A. T. M. et al. Embryo production and quality of Holstein heifers and cows supplemented with $\beta$-carotene and tocopherol. Animal Reproduction Science (in press) 2008.

SHAW, D. W.; FARIN, P. W.; WASHBURN, S. P. et al. Effect of retinol palmitate on ovulation rate and embryo quality in superovulated cattle. Theriogenology, v.44, n.1, p.51-58, 1995.

WHALEY, S. L.; HEDGPETH, V.S.; FARIN, C. E. et al. Influence of injection of vitamin A before mating on oocyte development, follicular hormones and ovulation in gilts fed high-energy diets. Journal of Animal Science, v.78, n.6, p.1598-1607, 2000.

YANG, M. Y.; FORTUNE, J. E. The capacity of primordial follicles in fetal bovine ovaries to initiate growth in vitro develops during mid-gestation and is associated with meiotic arrest of oocytes. Biology of Reproduction (in press) 2008 


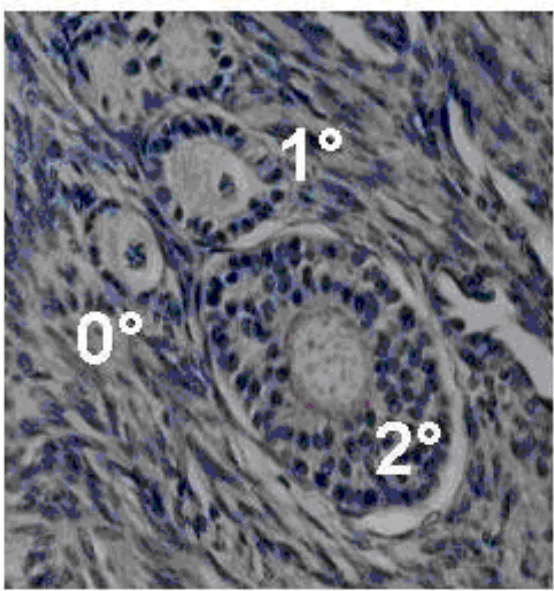

Figure 1 - Stained section of ovary from mature cow illustrating three stages of follicle development: $0^{\circ}$, primordial follicle; $1^{\circ}$, primary follicle and $2^{\circ}$, secondary follicle.

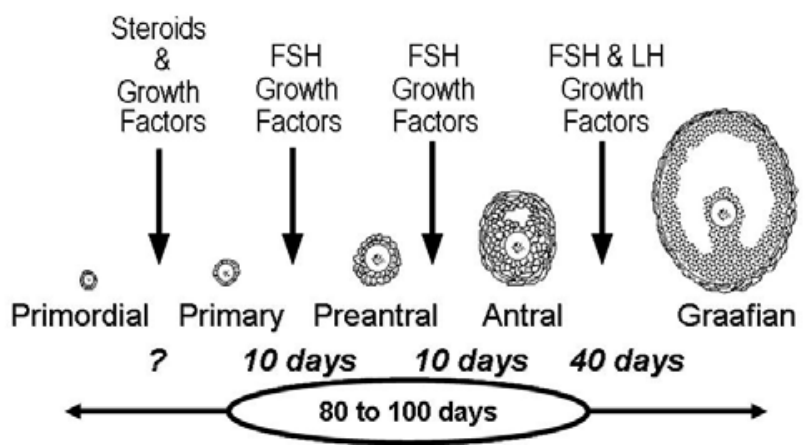

Figure 2 - Bovine folliculogenesis with approximate timeline for each stage and examples of hormones and factors that regulate transition from one stage to the next

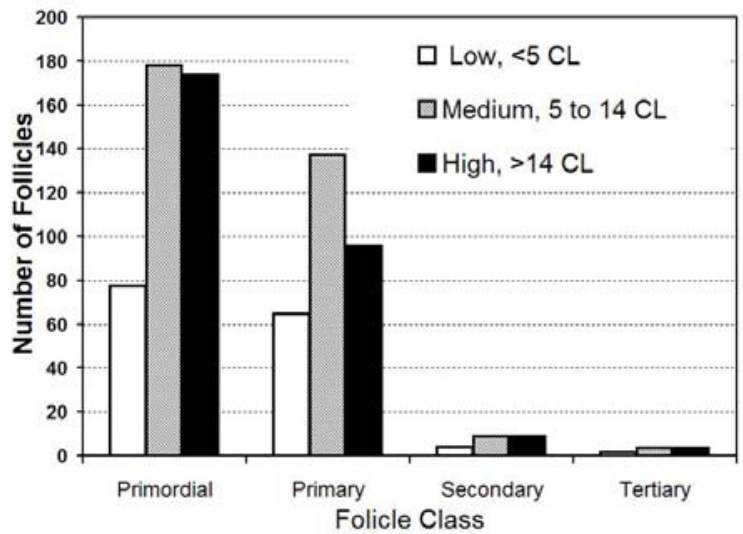

Figure 3 - Number of microscopic follicles of different classes in one ovary excised before the contralateral ovary was subjected to superovulation. The number of corpora lutea (CL) after superovulation was grouped for lower, middle and upper thirds of responders $(n=27)$. Adapted from Cushman et al., 1999.

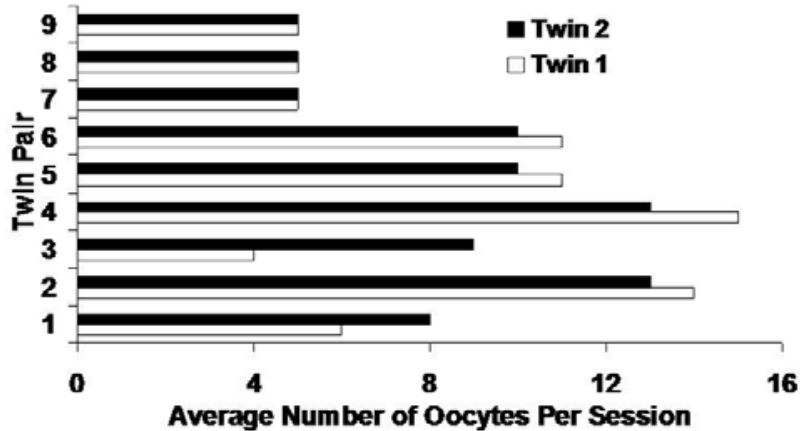

Figure 4 - Number of oocytes recovered during 11 serial ovum pick up sessions for each member of 9 pairs of monozygotic German Simmental twin cows. Adapted from Machado et al., 2005.

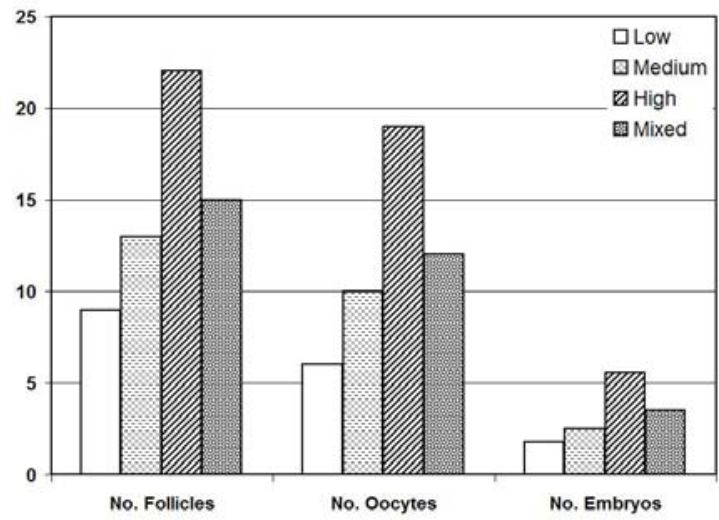

Figure 5 - Number of follicles, oocytes and embryos generated by ovum pick up and in vitro fertilization among 112 cows with an average of 5.9 sessions per animal. The response rate was classified as low, medium, high or mixed based on number of follicles punctured and number of oocytes collected. Adapted from De Roover et al., 2005. 